процессе : Материалы IV Всероссийской научно-практической конференции с международным участием / Отв. ред. Я. А. Чиговская-Назарова. - Глазов, 2011. - С. 316-318.

11. Ионова М. С. Характеристика социального интеллекта подростков, склонных к Интернет-зависимому поведению / М. С. Ионова, О. И. Чернобровкина // Новая наука : от идеи к результату : Международное научное периодическое издание по итогам Международной научно-практической конференции, (Сургут, 22 февраля 2017). - Стерлитамак : АМИ, 2017. - № 2 - 2. - С. 72 - 74.

12. Психология А - Я : психодиагностические методики, тренинги [Электронный ресурс]. - Режим доступа : http://azps.ru/tests/kit/generaliz_a.html.

13. Тарасова Т. В. Использование социальных сетей в реализации коммуникативной функции общения / Т. В. Тарасова, Р. С. Тарасов, В. Р. Мухадинов, И. В. Саушев // Гуманитарий : актуальные проблемы науки и образования. - 2015. - № 4 (32). - С. 54-65.

14. Терехова Е. В. Профилактическая и коррекционная работа психолога с подростками, склонными к компьютерной зависимости : методическая разработка / Е. В. Терехова. - Ярославль, 2013. - 61 с.

15. Янг К. Диагноз - Интернет-зависимость [Электронный ресурс] / К. Янг. - Режим доступа : http://www.narcom.ru/publ/info/665.

\title{
Чернова Е.O. \\ Методические основы исследования социально-психологических особенностей членов подростково-молодежных уличных криминальныхт группировок
}

ФГБНУ «Институт педагогики, психологии и сочиильных проблем»

(Россия, Казань)

doi: $10.18411 / l j-31-01-2018-28$

idsp: 000001:lj-31-01-2018-28

\section{Аннотация}

В статье обосновывается необходимость и целесообразность применения комплексных методик исследования социально-психологических особенностей членов подростково-молодежных уличных криминальных группировок. Методика исследования предполагает использование качественно-количественных методов. На основе выделенных эмпирических показателей искомого понятия обосновывается диагностический инструментарий.

Ключевые слова: методика, методология, социальная психология, субъектность, подростково-молодежные уличные криминальные группировки, социальноадаптационный потенциал личности

Исследование социально-психологических особенностей членов подростковомолодежных уличных криминальных группировок (далее - группировок) предполагает использование полипарадигмального подхода. Поясняя, отметим, что феномен группировок в социальной психологии изучен не достаточно. Имеющийся задел в научных исследованиях по данной проблематике не столько теоретизирован, сколько сконцентрирован на эмпирическом изучении отдельных особенностей несовершеннолетних правонарушителей, о чем мы уже отмечали в своих предыдущих работах [4, 5]. Вместе с тем, социально-психологические особенности личности несовершеннолетних правонарушителей и особенности личности членов группировок вовсе не предполагают совпадения исследовательских полей. В последнем случае акцентируется системный подход и фиксируется аспект проблемы групповой идентичности. В этой связи, методология изначально отлична. Выбор методологии предполагает не только теоретическое обоснование проблемы исследования, но выбор методов исследования, на чем стоит остановиться более подробно.

Наиболее общими методами исследования являются дедуктивный метод и аналитический метод. Поскольку сама проблема находится в поле междисциплинарных исследований, выбор методов сбора эмпирии может происходить в рамках различных наук. Из них большая часть используется в области социальной психологии, но часть методик может быть заимствована из других областей научного знания. Исходя из 
поставленных задач, необходимо сконцентрироваться на поиске и подборе диагностического инструментария для фиксации состояния следующих основных эмпирических признаков искомого понятия: мотивационные особенности подростков, склонности к агрессивному поведению, ценностно-смысловые ориентации, рефлексивные особенности подростков-членов группировок. К каждой задаче необходим подбор релевантных методик. Причем, для повышения валидности исследования желательно использовать не одну, а комплекс методик (приведены в таблице 1).

Таблища 1

Выбор и обоснование методик исследования социально-психологических особенностей членов группировок

\begin{tabular}{|c|c|}
\hline Методика & Цель применения \\
\hline $\begin{array}{c}\text { Методика М.Рогова } \\
\text { Методика А.Н. Грязнова }\end{array}$ & $\begin{array}{c}\text { Исследование ценностно-смысловых ориентация и } \\
\text { факторов социальных отношений внутри } \\
\text { специфических социальных групп и с внешним } \\
\text { окружением (ценностный аспект, мотивационный } \\
\text { аспект) }\end{array}$ \\
\hline $\begin{array}{c}\text { Тест-опросник акцентуаций характера } \\
\text { К.Леонгарда-К.Шмишека }\end{array}$ & $\begin{array}{l}\text { Исследование социально-адаптационного } \\
\text { потенциала }\end{array}$ \\
\hline $\begin{array}{c}\text { Тест-опросник мотивации достижения } \\
\text { А.Мехрабиана }\end{array}$ & $\begin{array}{c}\text { Исследование субъектных особенностей через } \\
\text { мотивацию достижения } \\
\text { Исследование социально-адаптационного } \\
\text { потенциала }\end{array}$ \\
\hline $\begin{array}{c}\text { Методика определения индивидуальной меры } \\
\text { рефлексивности А.В. Карпова }\end{array}$ & Исследование рефлексивных особенностей \\
\hline $\begin{array}{c}\text { Шкала социально-психологической } \\
\text { адаптированности (шкала СПА) К.Роджерса и } \\
\text { Р.Даймонда }\end{array}$ & $\begin{array}{c}\text { Исследование социально-адаптационного } \\
\text { потенциала }\end{array}$ \\
\hline $\begin{array}{c}\text { Метод кейс стадии (глубинные интервью, изучение } \\
\text { документов) }\end{array}$ & $\begin{array}{c}\text { Исследование социально-адаптационного } \\
\text { потенциала }\end{array}$ \\
\hline
\end{tabular}

Как следует из данных, представленных в таблице 1, для исследования выбран интегративный методический подход, предполагающий использование качественноколичественных методик. Большая часть из них принадлежит к полю психологии. Цель использования количественных методов (естественнонаучная парадигма) - «измерение» феномена путем установления повторяемости его признаков. Помимо основных количественных, используются и качественные методики (гуманитарная парадигма - кейс стади), цель их использования - получение глубинной информации по тем же признакам, с погружением во внутренний рефлексивный мир испытуемых.

Интеграция методик призвана эмпирически обосновать и доказать разработку социально-психологического и педагогического механизмов профилактики вовлечения подростков в группировки. Основные требования, которым должен отвечать используемый инструментарий: показатели должны быть операционализированы с тем, чтобы была возможность эмпирической их фиксации. Во-вторых, методики должны соответствовать возрасту и интеллектуальному развитию испытуемых, в связи с чем, первично необходима апробация инструментария. В-третьих, важна комплексность использования методик. Диагностический инструментарий базируется на опросных методах, поскольку предполагает оценочные суждения подростков.

В исследовании целесообразно сделать акцент на изучении ценностно-смысловой сферы подростков, так как она напрямую обусловливает функционирование субкультур внутри группировок и подверженность подростков вовлечению в них. Мы полагаем, что ценностно-смысловая сфера личности подростков является ведущим фактором риска, поскольку формирует уязвимость подростков с точки зрения их социальной адаптации. Здесь мы напрямую подошли к понятию «социально-адаптационный потенциал личности» подростков, на которое мы опираемся в исследовании особенностей членов 
группировок. Гипотетически, чем выше социально-адаптационный потенцал личности подростков, тем выше их устойчивость к возможному вовлечению в группировки.

Методика М.Рогова и методика А.Грязнова, разработанные, в свою очередь, на основе и с учетом методики М.Рокича, выступают диагностическим инструментарием для изучения ценностно-смысловой сферы личности подростков, а также для изучения уровня развития их социально-адаптационного потенциала. Иерархизация ценностей испытуемыми позволяет зафиксировать место и роль факторов социальных отношений в микрогруппе, ценностей самоутверждения, авторитета, лидерства. В то же время, важно выявить и место ценностей негативного характера - таких как склонность к употреблению ПАВ, где актуальна методика А.Н. Грязнова [1].

Уровень социально-адаптационного потенциала личности подростков может быть выявлен на основе опросной методики Г.Шмишека и К.Леонгарда, позволяющей диагностировать акцентуации характера как склонности к определенным позитивным или негативным векторам социального поведения. Мотивационные особенности личности подростков фиксируемы при помощи теста-опросника А. Мехрабиана для измерения мотивации достижения (ТМД) [3]. Целью при этом является определение субъектной направленности действий личности, одновременно позволяющей говорить о степени развития социально-адаптационного потенциала личности. Предполагаемые устойчивые мотивы личности подростка - стремление к успеху и избегание неудач свидетельствуют о доминировании одной из выделенных групп мотивов и позволяют диагностировать субъектную сущность личности. В свою очередь, высокая субъектность способствует развитию его социально-адаптационного потенциала. Тест применяется в форме опросника.

Определение индивидуальной меры рефлексивности производится с помощью методики А.В. Карпова и В.В. Пономаревой, инструментарием также служит опросник [2]. Рефлексивность подразумевает адекватность восприятия подростками окружающей действительности, ее отражения и мысленной переработки. Выявление социальноадаптационного потенциала подростков осуществляется также при помощи использования методики «шкала социально-психологической адаптированности (шкала СПА)» К.Роджерса и Р.Даймонда [6]. Действие методики направлено на определение особенностей периода адаптации личности подростка с помощью таких показателей как самовосприятие, стремление к доминированию, приятие «другого», интернальность. Диагностика позволяет определить, насколько адекватны переживания подростком кризисные ситуации, в какой мере он готов принимать или отвергать внешние условия. Методика К.Роджерса и Р.Даймонда диагностирует уровень адаптации или дезадаптации подростков к условиям внешней среды.

Помимо перечисленных «количественных» методик, в комплексной диагностике социально-адаптационного потенциала личности применяется метод кейс стадии (case study- исследование случая). Он применим в контексте изучения биографий членов группировок, а также бывших членов группировок, с целью глубинного изучения тех ресурсов, которые позволили им преодолеть криминальное прошлое и успешно пройти социальную адаптацию. Метод кейс стади используется как дополнительный для глубинного изучения отдельных аспектов проблемы.

Таким образом, методические основы исследования социально-психологических особенностей членов группировок предполагают использование комплексных методов. Основными принципами исследования при этом являются непротиворечивость (используемые методы не должны противоречить друг другу); комплексность, о чем сказано выше; анонимность; интегративность и сочетаемость методик; выборочность 
(испытуемые проходят предварительный отбор с помощью анкеты-фильтра). Совокупность данных принципов призвана обеспечить «чистоту» эксперимента.

$$
* * *
$$

1. Грязнов, А.Н. Терциарная социализация личности больных алкоголизмом и наркоманией: Дис...д-ра псих. Наук: 19.00 .05 / А.Н. Грязнов. - Ярославль, 2008. - 410 с.

2. Методика определения индивидуальной меры рефлексивности А.В. Карпова и В.В. Пономаревой (эл. pecypc) URL: http://www.studfiles.ru/preview/4016868/

3. Тест-опросник мотивации достижения А.Мехрабиана (эл. ресурс) URL: http://psychology-info.ru/mehrab/

4. Чернова Е.О. Феномен подростково-молодежных уличных криминальных группировок как проблема исследований социальной психологии / Е.О. Чернова // AKADEMICKA PSYCHOLOGIE. - 2016. - №2. - C.45-48.

5. Чернова Е.О., Грязнов А.Н. Проблема подростково-молодежных уличных криминальных группировок в теоретическом поле социальной психологии / Е.О. Чернова, А.Н. Грязнов // Казанский педагогический журнал. - 2016. - №4 (117). - С.159-162.

6. Шкала социально-психологической адаптированности (эл. pecypc) URL: http://spkaltan.ucoz.net/praktikum/programma_issledovanija_n-letnego.pdf 